\title{
MONOTONICITY OF GENERALIZED FURUTA TYPE FUNCTIONS
}

\author{
JiANGTAO YUAN AND GUOXING Ji
}

Abstract. The monotonicity of generalized Furuta type operator function $F_{S_{0}}(r, s)=C^{\frac{-r}{2}}\left(C^{\frac{r}{2}}\left(A^{\frac{t}{2}}\right.\right.$ $\left.\left.B^{p} A^{\frac{t}{2}}\right)^{s} C^{\frac{-r}{2}}\right)^{\frac{(p+t) s_{0}+r}{(p+t) s+r}} C^{\frac{-r}{2}}$ is discussed via the equivalent relations between operator inequalities. Let $-1 \leqslant t<0, p \geqslant 1(p+t \neq 0), C \geqslant A \geqslant B \geqslant 0$ with $A>0$. It is shown that, for each $s_{0}$ such that $\frac{t}{p+t}<s_{0}$, the function $F_{s_{0}}(r, s)$ is decreasing for both $r \geqslant-t$ and $s \geqslant \max \left\{1, s_{0}\right\}$. Moreover, some examples are given which imply that, for each $s_{0} \geqslant 1$ and $r \geqslant-t$, the monotone interval $\left[s_{0}, \infty\right)$ of $s$ in $F_{s_{0}}(r, s)$ is unique in the interval $\left[-\frac{r}{p+t}, \infty\right)$.

Mathematics subject classification (2010): 47A63, 47B15, 47B65.

Keywords and phrases: Positive operator, Loewner-Heinz inequality, Furuta inequality.

\section{REFERENCES}

[1] T. ANDo AND F. HiAI, Log majorization and complementary Golded-Thompson type inequality, Linear Algebra Appl. 197 (1994), 113-131.

[2] J. C. Bourin AND E. RicARD, An asymmetric Kadison's inequality, Linear Algebra Appl. 433 (2010), 499-510.

[3] M. FujiI AND E. KAMEI, Mean theoretic approach to the grand Furuta inequality, Proc. Amer. Math. Soc. 124 (1996), 2751-2756.

[4] T. FURUTA, $A \geqslant B \geqslant 0$ assures $\left(B^{r} A^{p} B^{r}\right)^{\frac{1}{q}} \geqslant B^{\frac{p+2 r}{q}}$ for $r \geqslant 0, p \geqslant 0, q \geqslant 1$ with $(1+2 r) q \geqslant p+2 r$, Proc. Amer. Math. Soc. 101 (1987), 85-88.

[5] T. FURUTA, Extension of the Furuta inequality and Ando-Hiai log-majorization, Linear Algebra Appl. 219 (1995), 139-155.

[6] T. FURUTA, Monotonicity of order preserving operator functions, Linear Algebra Appl. 428 (2008), 1072-1082.

[7] T. FuRUTA, Invitation to Linear Operators, Taylor \& Francis, London, 2001.

[8] M. ITO AND T. YAmAZAKI, Relations between two inequalities $\left(B^{\frac{r}{2}} A^{p} B^{\frac{r}{2}}\right)^{\frac{r}{p+r}} \geqslant B^{r}$ and $\left(A^{\frac{p}{2}} B^{r} A^{\frac{p}{2}}\right)^{\frac{p}{p+r}} \leqslant A^{p}$ and its applications, Integral Equations Operator Theory 44 (2002), 442-450.

[9] M. ITO, T. YAMAZAKI AND M. YANAGIDA, Genaralications of results on relations between Furutatype inequalities, Acta Sci. Math. (Szeged) 69 (2003), 853-862.

[10] V. LAURIC, $\left(C_{p}, \alpha\right)$-hyponormal operators and trace-class self-commutators with trace zero, Proc. Amer. Math. Soc. 137 (2009), 945-953.

[11] K. Tanahashi, Best possibility of Furuta inequality, Proc. Amer. Math. Soc., 124 (1996), 141-146.

[12] M. Uchiyama, Some exponential operator inequalities, Math. Inequal. Appl. 2 (1999), 469-471.

[13] M. UchiYama, Criteria for monotonicity of operator mean, J. Math. Soc. Japan 55, 1 (2003), $197-$ 207.

[14] X. WANG AND Z. GAO, A note on Aluthge transforms of complex symmetric operators and applications, Integral Equations Operator Theory 65 (2009), 573-580.

[15] T. YamaZaKi, Simplified proof of Tanahashi's result on the best possibility of generalized Furuta inequality, Math. Inequal. Appl. 2 (1999), 473-477.

[16] M. YAnAgIDA, Powers of class wA $(s, t)$ operators associated with generalized Aluthge transformation, J. Inequal. Appl. 7, 2 (2002), 143-168.

[17] C. Yang And J. YuAn, On class $w F(p, r, q)$ operators, Acta Math. Sci. Ser. A Chin. Ed. 27 (2007), 769-780. 
[18] J. YUAN, Furuta inequality and q-hyponormal operators, Oper. Matrices 4, 3 (2010), 405-415.

[19] J. YUAN, Classified construction of generalized Furuta type operator functions, II, Math. Inequal. Appl. 13, 4 (2010), 775-784.

[20] J. YUAN AND Z. GAO, The Furuta inequality and Furuta type operator functions under chaotic order, Acta Sci. Math. (Szeged) 73 (2007), 669-681.

[21] J. YUAN AND Z. GAO, The operator equation $K^{p}=H^{\frac{\delta}{2}} T^{\frac{1}{2}}\left(T^{\frac{1}{2}} H^{\delta+r} T^{\frac{1}{2}}\right)^{\frac{p-\delta}{\delta+r}} T^{\frac{1}{2}} H^{\frac{\delta}{2}}$ and its applications, J. Math. Anal. Appl. 341 (2008), 870-875.

[22] J. Yuan And Z. GaO, Complete form of Furuta inequality, Proc. Amer. Math. Soc. 136, 8 (2008), $2859-2867$.

[23] X. Zhan, Matrix Inequalities, Springer Verlag, Berlin, 2002. 